\title{
A Case of Rotational Vertebral Artery Syndrome after Vertebral Artery Dissection
}

\author{
Song Jae Lee, Ha Young Byun, Seung Hwan Lee, and Jae Ho Chung (D) \\ Department of Otolaryngology-Head and Neck Surgery, College of Medicine, Hanyang University, Seoul, Korea \\ 추골 동맥 박리 후 발생한 회전성 추골 동맥 증후군 1예 \\ 이송재 · 변하영 · 이승환 · 정재호 \\ 한양대학교 의과대학 이비인후-두경부외과학교실
}

\author{
Received August 19, 2019 \\ Revised September 25, 2019 \\ Accepted September 27, 2019 \\ Address for correspondence \\ Jae Ho Chung, MD, PhD \\ Department of Otorhinolaryngology \\ Head and Neck Surgery, \\ College of Medicine, \\ Hanyang University, 222 Wangsimni-ro, \\ Seongdong-gu, Seoul 04763, Korea \\ Tel $+82-2-2290-8580$ \\ Fax +82-2-2290-3335 \\ E-mail jaeho.chung.md@gmail.com
}

Rotational vertebral artery syndrome (RVAS), also called Bow-Hunter syndrome, is characterized by position-aggravated reversible vertebra-basillarischemia. By rotating the head to one side, the mechanical compression of a dominant vertebral artery (VA) in the setting of a hypoplastic contralateral VA might cause tinnitus, vertigo and syncope. A 60-year-old male experienced recurrent tinnitus and vertigo while rotating the head to the right side. Neck CT images showed no abnormal structures near the course of both VAs. In 3-phase dynamic neck CT angiography, a focal vertebral artery dissection was identified at the right C6 transverse foramen. Close observation and anticoagulation therapy were started to prevent thrombo-embolic complications. Herein, we report a case of RVAS with vertebral artery dissection with a review of the literatures. Korean J Otorhinolaryngol-Head Neck Surg 2020;63(5):228-32

Key Words Vertebral artery · Vertebral artery dissection · Vertigo.

\section{서 론}

회전성 추골 동맥 증후군(rotational vertebral artery syndrome)은 특정 자세로 증상이 유발되는 가역적인 척추 뇌저 동맥 순환 부전의 하나이다. ${ }^{1,2)}$ 현훈, 안진, 이명, 복시, 발음곤란, 감각 및 운동 이상, 실신의 증상이 발생하며, 고개 를 돌리는 특징적인 자세 때문에 'Bow Hunter syndrome'으 로도 불린다. ${ }^{3-5)}$ 한쪽 추골 동맥의 선천적 형성부전, 위축증, 후천적으로 좁아지거나 막혀서 반대편 추골 동맥이 주된 혈 류 공급을 담당하고 있는 상황에서 특징적인 고개 돌림으로 인해 일시적인 혈류 공급이 차단되는 경우가 가장 많다. ${ }^{6,7)}$ 주된 호발 부위는 경추 1 번과 2 번 사이이다. ${ }^{8)}$

회전성 추골 동맥 증후군은 흔치 않은 질환으로 아직까지

This is an Open Access article distributed under the terms of the Creative Commons Attribution Non-Commercial License (https://creativecommons.org/licenses/by-nc/4.0) which permits unrestricted non-commercial use, distribution, and reproduction in any medium, provided the original work is properly cited.
진단과 치료에 있어서 정립된 지침이 없다. ${ }^{3)}$ 다만 현재까지의 보고에 따르면 역동성 혈관 조영술을 이용하여 진단한 경우 가 가장 많으며, 추골 동맥 주행 경로상 압박 구조물이 관찰 되는 경우 수술적 치료를 하고, 그렇지 않은 경우에는 항응 고 약물 치료 및 고개 돌림 제한 교육을 통한 경과 관찰을 한다. ${ }^{1,2)}$

저자들은 우측으로 고개를 돌릴 때마다 어지럼증이 발생 하는 환자에서 국소적 추골 동맥 박리로 인해서 발생한 회전 성 추골 동맥 증후군을 경험하여 이에 문헌 고찰과 함께 보 고하는 바이다.

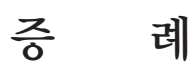

60세 남자 환자가 7일 전부터 시작된 반복적인 어지럼증을 주소로 내원하였다. 작년 여름에 처음 증상이 발생하였고, 당 시 증상 심하지 않아서 치료받지 않았다. 어지럼 양상은 빙글 
빙글 도는 어지럼은 아니었고 특징적으로 우측으로 고개를 돌렸을 때 어지럼이 유발되었다. 어지럼이 심할 때는 우측 귀 에서 이명이 들리고, 눈앞이 희미해진다고 하였다. 환자는 고 혈압, 고지혈증, 당뇨로 약물 치료 중이었다.

외래에서 시행한 어지럼 설문지에서 머리를 우측으로 빠 르게 돌리면 증상이 심해진다고 기술하였다. 이학적 검사상 양측 고막은 정상이었고, 순음 청력 검사상 청력 역치는 우 측 $38 \mathrm{~dB}$, 좌측 $33 \mathrm{~dB}$ 로 측정되었다. 비디오 안진 검사상 자 발 안진은 없었고, 갸웃 검사(roll test)에서 우측을 바라볼 때 수직 안진이 관찰되면서 말 어눌함, 사지 경직 소견을 보 였다(Fig. 1). 비디오 두부 충동 검사, 회전의자 검사에서는 특이 소견은 없었다. 병력을 바탕으로 우측 양성 돌발성 자 세 유발 현훈증을 의심하였으나 검사 결과와 맞지 않았다. 수직 안진을 유발시킬 수 있는 다른 중추 신경계 병변을 감 별하기 위해 뇌 자기공명 및 자기공명 혈관 조영술을 시행하 였고, 좌측 추골 동맥의 형성 저하 소견 외 다른 이상 소견은 없었다(Fig. 2). 자기공명 혈관조영술 결과를 바탕으로 우측 추골 동맥이 주된 혈류 공급원이고, 우측으로 고개를 돌리 면 순간적으로 우측 추골 동맥의 혈류 공급이 중단되어 증 상이 유발된 것을 의심할 수 있었다. 따라서 추골 동맥의 주 행 경로에서 외부에서 압박을 하는 구조물이 있는지 확인하 기 위해서 조영제를 사용하여 경부 컴퓨터단층촬영을 시행 하였으나, 영상에서 우측 추골 동맥의 주행 경로 중 동맥을 압박할 수 있는 구조물은 관찰되지 않았다.

이후 고개를 돌릴 때 우측 추골 동맥의 혈류 공급 여부를 확인하기 위해 3상 경부 컴퓨터단층촬영 혈관 조영 검사를 시행하였다. 조영제 주입 후 1 상에서 고개를 우측으로 돌린 채 촬영을 하였고, 2 상과 3 상에서는 고개를 바로 한 채 촬영 을 하였다. 혈관 조영 검사상 쇄골하 동맥에서 나온 추골 동 맥이 6번째 경추 가로 구멍에 들어가는 경로에 국소적으로 동맥 박리 소견이 관찰되었다(Fig. 3). 또한 1상에서 추골 동 맥 혈류 공급이 줄어 들었고(Fig. 4A), 3상에서는 혈류 공급 이 다소 회복되는 것을 확인하였다(Fig. 4B). 이상의 검사 결 과를 바탕으로 우측 추골 동맥에 국소적인 동맥 박리가 발생 하였고, 이로 인해 우측으로 고개를 돌리면 내강이 좁아져서 일시적으로 혈류 공급이 줄어 들면서 증상이 발생하였다고 결론지었다. 뇌경색으로 인한 합병증을 예방하기 위해 항응 고약제 복용 및 고개 돌림 제한할 것을 교육하였으며, 추적 진료에서 추가적인 증상 발생없이 경과 관찰 중이다.

\section{고 찰}

회전성 추골 동맥 증후군은 특징적으로 고개 돌리는 자세
에 의해서 추골 동맥이 일시적으로 폐쇄되어 어지럼증, 안진, 이명, 복시, 실신 등의 증상이 발생한다.") 이전 보고에 따르면 정상인에서도 약 $9 \%$ 에서 증상 없이 머리 회전으로 추골 동맥 폐쇄가 관찰된다고 한다. ${ }^{10)}$ 따라서 증상이 발생하려면 한쪽 추골 동맥이 선천적으로 형성 저하증, 위축증, 무형성증 그리 고 후천적 내강 폐쇄가 있어야 하며, 이러한 전제 조건하에 고개 돌림에 의한 일과성 허혈 발작으로 증상이 발생할 수 있 다. ${ }^{3)}$ 추골 동맥의 압박은 가로 구멍(transverse foramen)에 뼈 돌기(osteophyte)가 생겼고, 고개를 돌리면 뼈돌기에 의해서 추골 동맥이 압박되어 증상이 발생한 경우가 가장 많다고 알 려져 있다." 그 외에 추골 동맥 주변의 인대, 근육 등의 외부 구조물의 압박 혹은 동맥 경화, 동맥박리의 내부적인 요인에 의해서 발생할 수 있다.8) 추골 동맥박리는 자연적으로 발생 하거나 경부의 과도한 신전 자극에 의해서 발생 할 수 있는 것으로 보고된다. ${ }^{11)}$ 본 증례에서는 환자가 고혈압, 당뇨, 고지 혈증의 동맥경화 위험 인자를 가지고 있어 동맥경화와 동맥 박리가 복합적으로 작용하여 회전성 추골 동맥 증후군을 유 발한 것으로 생각해 볼 수 있다. 또한 우측 추골 동맥에 발생 한 동맥박리로 인해 혈관의 내측에 가성 내강(false lumen)이 형성되었고, 외측의 진성 내강(true lumen)으로 혈류 공급이 되는 것으로 확인되었다(Fig. 3). 따라서 우측 고개 돌림으로 추골 동맥이 신전되어 박리된 혈관에서의 진성 내강이 좁아 지면서 증상이 발생한 것으로 추측해 볼 수 있다.

회전성 추골 동맥 증후군에서 안진은 주로 수평과 수직이 혼재된 양상이나 수직 안진이 주된 양상이며, 그중에서 하방 안진이 많다. ${ }^{12}$ 본 증례는 수직 안진 중 상방 안진이 주로 관 찰되었다. 상방 안진은 상반고리관 신경로의 병변 혹은 연수 의 병변으로 발생하는 것으로 알려져 있다. ${ }^{13)}$ 상반고리관 신 경로의 병변은 상반고리관에 혈류를 공급하는 앞전정동맥이 일시적 허혈 상태가 되면서 발생 가능하며, 다른 내이 동맥 에 비해 측부 순환이 덜 발달되어 허혈에 상대적으로 취약 한 것으로 알려져 있다. ${ }^{7}$ 상방 안진을 유발하는 연수의 병변 은 연수-교뇌 이행부의 문제로 주로 발생할 수 있다. 본 증례 에서는 환자가 우측으로 고개를 돌릴 때 상반고리관 신경로 혹은 연수의 허혈이 발생하였고 이로 인해 상방 안진이 발생 한 것으로 추정해 볼 수 있다. 또한 전정계가 와우계보다 허 혈에 민감하기 때문에 어지럼증 발생 후 이명과 같은 청각 증상이 발생한 것으로 이해할 수 있다. ${ }^{14)}$

회전성 추골 동맥 증후군은 역동성 혈관 조영술로 진단 가 능하다. ${ }^{8)}$ 이는 침습적인 술기로 혈관 조영술 중 자세 변화에 따른 혈관 내 혈류의 변화를 즉시 확인 가능한 장점이 있다. 또한 경동맥 이중 초음파 검사를 회전성 추골 동맥 증후군의 진단에 활용한 증례가 보고되었으며, 비침습적이고 저비용, 


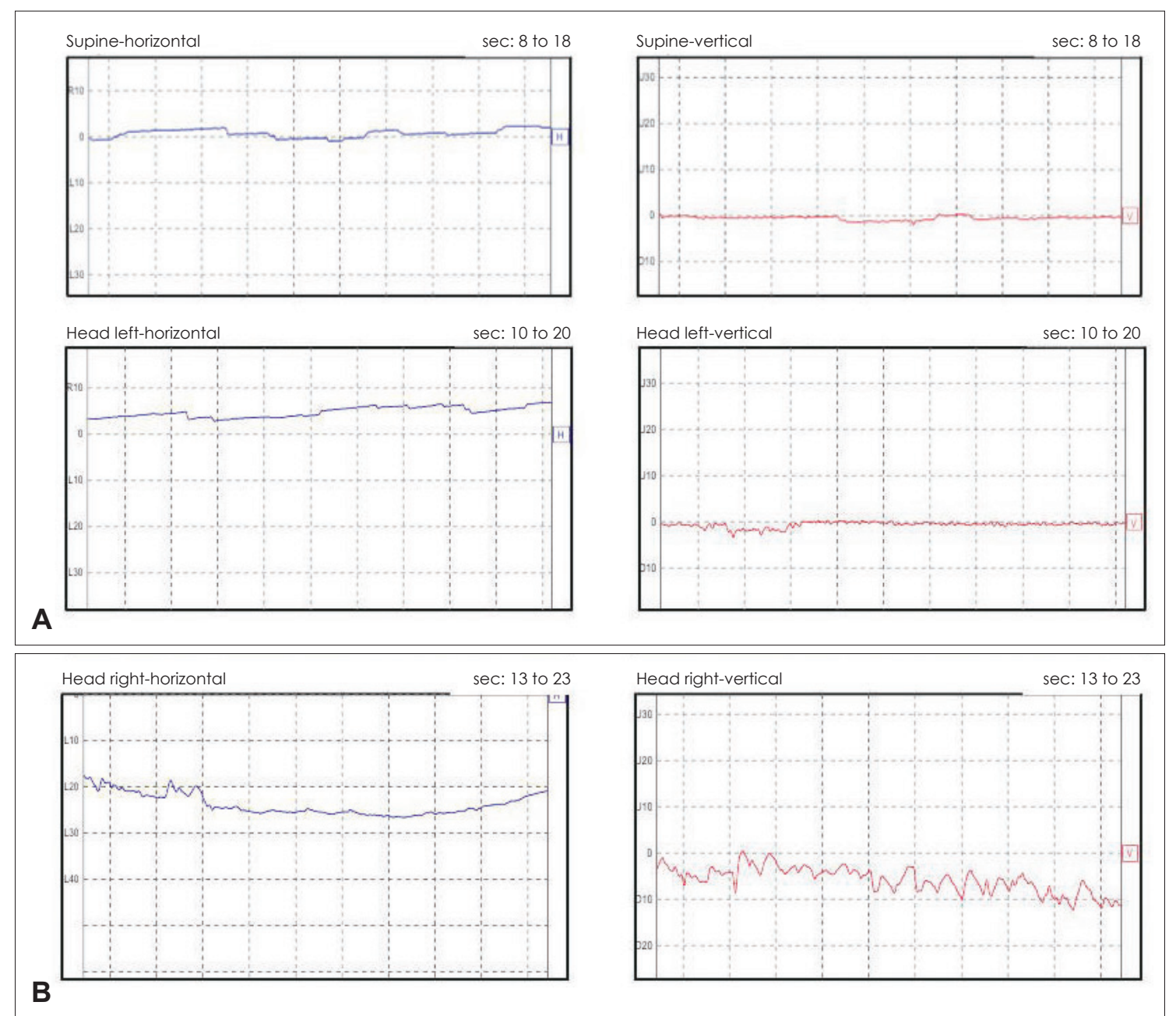

Fig. 1. Videonystagmographic finding of the patient during supine roll test. There's no nystagmus at supine and leftward head tilting position (A). At rightward head tilting position, vertical nystagmus was provoked (B).
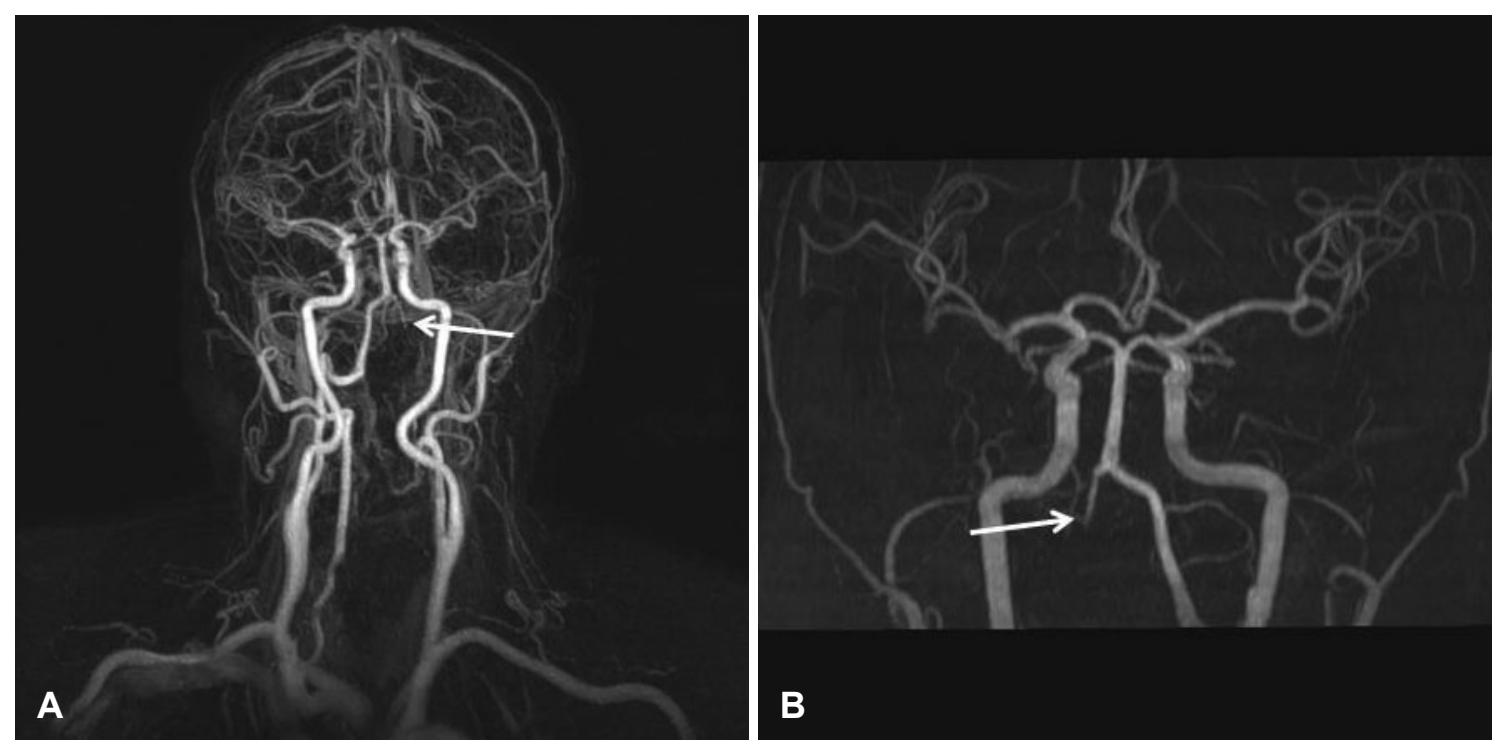

Fig. 2. Brain angiographic MRI finding. Narrowed left vertebral artery is noted (white arrows) (A and B). 
간편하게 할 수 있는 장점이 있으나 초음파 투과 능력의 한 계로 두개저 내부 혈관 확인이 어려운 단점이있다. ${ }^{6}$ 혈관 구 조 및 주변 구조물과의 관계를 파악 할 수 있는 컴퓨터단층 촬영 혈관 조영 검사 혹은 자기공명 혈관 조영 검사를 회전 성 추골 동맥 증후군 진단에 활용할 수 있다. ${ }^{3)}$ 또한 본 증례
와 같이 역동성 혈관 조영술과 비슷한 방법으로 컴퓨터단층 촬영 중 고개를 움직이면서 이에 따른 혈관 내 조영제의 농 도 및 혈관의 크기를 비교하여 회전성 추골 동맥 증후군을 진단할 수 있다.

회전성 추골 동맥 증후군의 치료는 내과적 치료, 외과적
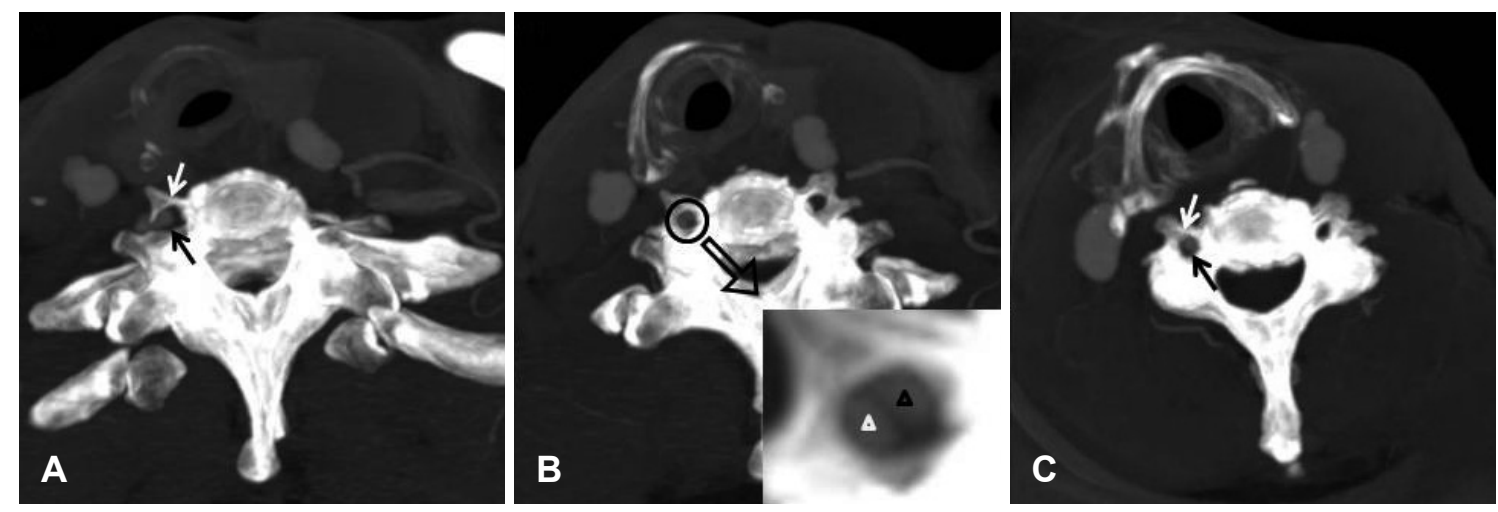

Fig. 3. Neck CT angiographic finding. Right vertebral artery (black arrow) is entering the C6 transverse foramen (white arrow) (A). After entering the $\mathrm{C} 6$ transverse foramen, arterial dissection was identified by showing true lumen (white arrowhead) and false lumen (black arrowhead) (B). At C5 transverse foramen (white arrow), lumen of right vertebral artery (black arrow) is patent (C).
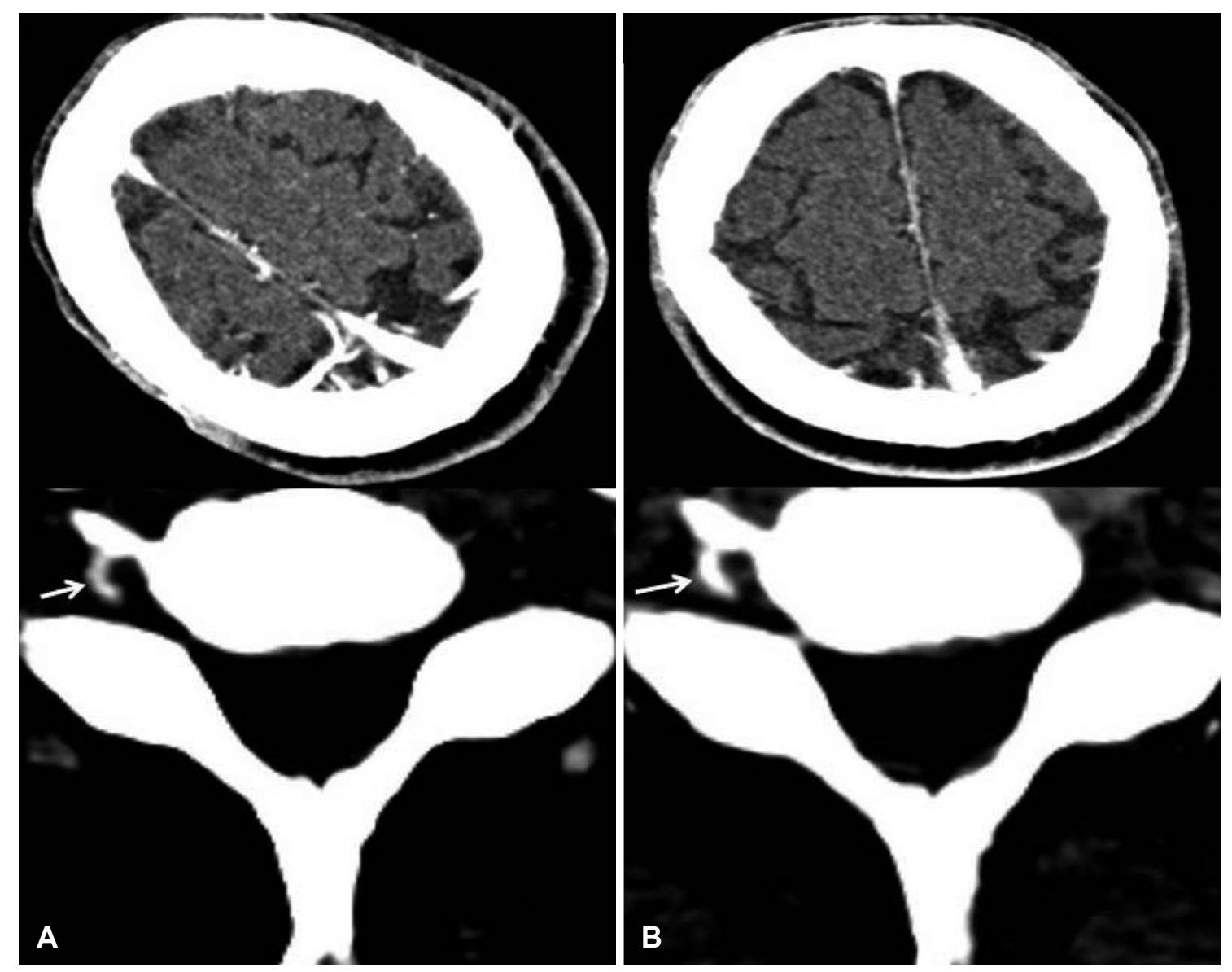

Fig. 4. 3-phase neck CT angiographic finding. Upper image shows head position and lower angiographic image shows size of true lumen. In phase 1, after tilting 90 degree to rightward, true lumen of vertebral artery is narrowed (white arrow) (A). In phase 3, after neutral position, true lumen of vertebral artery is slightly widened (white arrow) (B). 
치료, 혈관 중재술로 나뉜다. ${ }^{3)}$ 내과적 치료는 경부 보호대의 사용, 항응고약제를 사용하는 방법이며, 외과적 치료의 적응 증이 아닌 경우 혹은 외과적 치료 전에 시도해 볼 수 있다. 하지만 내과적 치료만 하는 경우 약 $50 \%$ 에서 뇌경색이나 신 경학적 이상 소견이 발생한다는 보고가 있기 때문에 외과적 치료가 필요한 경우가 많은 것으로 알려져 있다. ${ }^{10)}$ 외과적 치 료는 외부 구조물에 의해 추골 동맥에 압력이 가해질 경우 그 구조물을 제거하는 감압술을 시행하고, 관절이 불안정 하 거나 과도한 고개 돌림을 감소시키기 위해서 고정술을 시행 할 수 있다. ${ }^{5,15}$ 또한 심각한 박리 혹은 협착이 확인된 경우는 혈관 색전술, 혈관 성형술로 치료 가능하다. ${ }^{3)}$ 본 증례는 항응 고제 치료를 유지 중이며, 혈관을 누르고 있는 물리적인 구 조물은 없어 수술적 치료는 계획하지 않고 있으나, 향후 증 상이 악화되는 경우 혈관 중재술을 고려해 볼 수 있을 것이 라 생각한다.

본 증례에서는 침습적인 역동성 혈관 조영술 대신 비침습 적인 3상 경부 컴퓨터단층촬영 혈관 조영 검사를 이용하여 회전성 추골 동맥 증후군을 성공적으로 진단하였기에 문헌 고찰과 함께 보고하는 바이다.

\section{Acknowledgments}

None.

\section{Author Contribution}

Conceptualization: Jae Ho Chung, Seung Hwan Lee, Ha Young Byun. Funding acquisition: Jae Ho Chung. Resources: Jae Ho Chung, Seung Hwan Lee. Supervision: Jae Ho Chung, Seung Hwan Lee, Ha Young Byun. Visualization: Song Jae Lee, Ha Young Byun. Writing — original draft: Song Jae Lee. Writing — review \& editing: Jae Ho Chung, Song Jae Lee.

\section{ORCID}

Jae Ho Chung https://orcid.org/0000-0001-6884-7927

\section{REFERENCES}

1) Go G, Hwang SH, Park IS, Park H. Rotational vertebral artery compression: Bow Hunter's syndrome. J Korean Neurosurg Soc 2013;54(3):243-5.

2) Schelfaut S, Verhasselt S, Carpentier K, Moke L. Subaxial rotational vertebral artery syndrome: Resection of the uncinate process and anterior fusion can be sufficient!: Case report and review of the literature. J Spinal Disord Tech 2015;28(2):66-70.

3) Duan G, Xu J, Shi J, Cao Y. Advances in the pathogenesis, diagnosis and treatment of Bow Hunter's syndrome: A comprehensive review of the literature. Interv Neurol 2016;5(12):29-38.

4) Kuether TA, Nesbit GM, Clark WM, Barnwell SL. Rotational vertebral artery occlusion: A mechanism of vertebrobasilar insufficiency. Neurosurgery 1997;41(2):427-32.

5) Cai DZ, Roach RP, Weaver JP, McGillicuddy GT, Mansell ZM, Eskander JP, et al. Bow Hunter's syndrome in a patient with a right hypoplastic vertebral artery and a dynamically compressible left vertebral artery. Asian J Neurosurg 2018;13(1):133-5.

6) Kim S-H. A case of rotational vertebral artery syndrome diagnosed with color Doppler-assisted carotid duplex sonography imaging. Korean J Otorhinolaryngol-Head Neck Surg 2016;59(11):796-801.

7) Choi KD, Choi JH, Kim JS, Kim HJ, Kim MJ, Lee TH, et al. Rotational vertebral artery occlusion: Mechanisms and long-term outcome. Stroke 2013;44(7):1817-24.

8) Kang HS, Ahn S-K, Hur DG, Hwang S-H. A case of rotational vertebral artery syndrome treated by posterior cervical decompression. Korean J Otorhinolaryngol-Head Neck Surg 2012;55(2):107-10.

9) Dargon PT, Liang CW, Kohal A, Dogan A, Barnwell SL, Landry GJ. Bilateral mechanical rotational vertebral artery occlusion. J Vasc Surg 2013;58(4):1076-9.

10) Choi K-D, Shin H-Y, Kim JS, Kim S-H, Kwon O-K, Koo J-W, et al. Rotational vertebral artery syndrome: Oculographic analysis of nystagmus. Neurology 2005;65(8):1287-90.

11) Park KW, Park JS, Hwang SC, Im SB, Shin WH, Kim BT. Vertebral artery dissection: Natural history, clinical features and therapeutic considerations. J Korean Neurosurg Soc 2008;44(3):109-15.

12) Jung I, Jung J-M, Park MH. Rotatory vertebral artery syndrome in foramen magnum stenosis. Res Vestib Sci 2018;17(4):167-9.

13) Kim JS, Yoon B, Choi KD, Oh SY, Park SH, Kim BK. Upbeat nystagmus: Clinicoanatomical correlations in 15 patients. J Clin Neurol 2006;2(1):58-65.

14) Inui $H$, Murai $T$, Yane $K$, Matsunaga $T$. Brainstem ischemic damage following occlusion of the blood vessels in the rat's posterior cerebral circulation. Eur Arch Otorhinolaryngol 1996;253(3):176-81

15) Yamaguchi $S$, Horie N, Tsunoda $K$, Tateishi Y, Izumo T, Hayashi $\mathrm{K}$, et al. Bow Hunter's stroke due to stretching of the vertebral artery fenestration: A case report. NMC Case Rep J 2014;2(1):9-11. 